\title{
Risk and capital transfer in insurance groups
}

\author{
Nadine Gatzert • Hato Schmeiser
}

Published online: 14 October 2008

(C) Springer-Verlag 2008

\begin{abstract}
The aim of this paper is to analyze the effect of capital and risk transfer instruments (CRTIs) on a financial group's risk situation. In this respect, we extend previous literature by accounting for the conglomerate discount on firm value, which is a reduction in shareholder value due to diversification within the group. In general, CRTIs between parent and subsidiaries have a substantial effect on the diversification of risks, economic capital requirements, and default risk, which we study in detail for different types of CRTIs, including intra-group retrocession and guarantees. One main finding is that diversification effects within the group are much lower when taking into account conglomerate discount effects. We believe this aspect to be an important issue in the ongoing discussion on group solvency regulation and enterprise risk management.
\end{abstract}

Zusammenfassung Zielsetzung des vorliegenden Beitrags ist eine Analyse von Kapital- und Risikotransferinstrumenten innerhalb einer Versicherungsgruppe und deren Bedeutung für die Risikosituation. Die gesichtete Literatur zu dieser Thematik wird durch Berücksichtigung der Diversifikationseffekte auf den Marktwert des Unternehmens (Reduktion des Shareholder Value durch Diversifikation) erweitert. Grundsätzlich bewirken Kapital- und Risikotransferinstrumente eine Diversifikation innerhalb der Finanzgruppe und üben Effekte auf das ökonomische Kapital und das Insolvenzrisiko der einzelnen Unternehmen innerhalb der Gruppe und des

This article is based on Gatzert and Schmeiser (2008a) and has been presented by Nadine Gatzert at the annual meeting of "Deutscher Verein für Versicherungswissenschaft e.V." in March 2008. In addition to Gatzert and Schmeiser (2008a), the following contribution contains a selection of new numerical examples.

N. Gatzert ( $) \cdot$ H. Schmeiser

Universität St. Gallen, Institut für Versicherungswirtschaft,

Kirchlistrasse 2, 9010 St. Gallen, Switzerland

E-Mail: nadine.gatzert@unisg.ch 
Finanzkonglomerats insgesamt aus. In unserer Analyse zeigt sich, dass die Wirkung von Diversifikation innerhalb einer Finanzgruppe erheblich reduziert wird, falls die Rückkopplung auf den Shareholder Value Berücksichtigung findet. Wir halten diese Ergebnisse im Hinblick auf die aktuelle Diskussion zur Thematik der Gruppensolvenzbestimmung, aber auch für Fragen des Enterprise Risk Managements einer Versicherungsgruppe für bedeutsam.

\section{Introduction}

The recent trend toward consolidation in the financial sector has led to an increasing number of large financial groups and conglomerates that provide financial services in different sectors and countries. ${ }^{1}$ This development concerns insurance groups, too, which are often organized as parent-subsidiary structures. In general, conglomeration leads to a diversification of risks (the diversification benefit) and to a decrease in shareholder value (the conglomerate discount). Concerning the diversification of risks in a parent-subsidiary model, two concepts can be distinguished. First, grouplevel diversification arises if cash-flows of different legal entities in a group are not fully correlated. Second, down-streaming of diversification occurs if capital and risk transfer instruments (CRTIs) are in effect, which are legally enforceable agreements between parent and subsidiaries. These kind of agreements can only be offered by a firm according to its financial ability to cover these guarantees. Furthermore, legal restrictions may prohibit intra-group loss transfers.

Apart from diversification benefits, conglomeration generally leads to a conglomerate discount, i. e., a decrease in shareholder value. However, diversification benefits are typically determined without accounting for the reduction in shareholder value, even though a comprehensive analysis should account for a competitive situation within the group (i. e., shareholders and debtholders receive risk-adequate returns on their investments). This is an important aspect that has not received attention in the literature so far, even though it has major implications for group management decisions and solvency regulation.

The aim of this paper is to extend previous literature by assessing the impact of risk and capital management on an insurance group's risk situation by explicitly taking into account the conglomerate discount. Capital and risk transfers between parent and subsidiaries will have a substantial effect on the diversification of risks, economic capital requirements, and default risk, which we analyze in detail for different types of CRTIs, including intra-group retrocession and guarantees. We compare results for the parent-subsidiary model with a holding company and an integrated model. In this context, we aim to provide insight for enterprise risk management purposes in insurance groups as well as for group regulation.

We proceed as follows: For two entities in a group, diversification and insolvency risk are determined. Furthermore, we account for CRTIs and include a guarantee from

\footnotetext{
${ }^{1}$ A definition of financial conglomerates is given in Diereck (2004), p. 10: "In the most general sense, a financial conglomerate is a group of entities whose primary business is financial and whose regulated entities engage to a significant extent in at least two of the activities of banking, insurance and securities. According to this definition, bancassurance groups would qualify as financial conglomerate, but so would groups combining insurance and securities or banking and securities."
} 
parent to subsidiary and quota share retrocession, i. e., the parent pays a share of the subsidiary's liabilities. In the analysis, the conglomerate discount is considered by calculating the fair amount of equity capital (i. e., the present value of the equityholders' payoff equals their initial contribution) for each type of group. The conglomerate discount is quantified employing an option-pricing model framework; diversification benefit is calculated using the tail value at risk.

We consider the group perspective by calculating diversification benefit and joint default probabilities, as well as the position of the individual institutions, i. e., solvency capital and individual shortfall risk. This allows receiving a more detailed picture of the altered group situation. We conclude that for the considered conglomerate structures under competitive conditions, diversification regarding risk reduction does not matter to the extent frequently emphasized in the literature when diversification effects originating from the group structure and capital and risk transfer instruments are studied.

The remainder of the paper is organized as follows. Section 2 contains a literature review on diversification and conglomerate discount in financial groups. Section 3 introduces different corporate structures as well as capital and risk transfer instruments. Diversification benefit and conglomerate discount for individual firms and groups are considered in Sect. 4. Section 5 contains numerical examples to illustrate main effects and Sect. 6 summarizes the results.

\section{Literature review}

In the literature, diversification benefits and the conglomerate discount in financial groups have been treated from different perspectives. The diversification benefit is typically measured based on the conglomerate's economic capital relative to the sum of the stand-alone economic capital. In the context of regulation, Keller (2007); Luder (2007) discuss the Swiss Solvency Test on the group-level and how CRTIs are accounted for when measuring the solvency capital requirements of insurance groups in a parent-subsidiary structure. In a similar setting, Filipovic and Kupper (2007, 2008) derive optimal CRTIs that minimize the difference between available and required capital in an insurance group for convex risk measures, and thus focus on the group perspective. Freixas et al. (2007) compare the risk-taking incentives of stand-alone firms, holding company conglomerates, and integrated conglomerates, and show that diversification within integrated models can increase risk-taking incentives and thus lower social welfare relative to the stand-alone case.

In respect to the conglomerate discount, Berger and Ofek (1995) empirically show for the U.S. market that there was a reduction in firm value of between $13 \%$ and $15 \%$ between 1986 and 1991, which they attribute, in part, to overestimation and cross-subsidization. For financial firms, Laeven and Levine (2005) also observe a conglomerate discount and stress agency problems as a possible cause. In agency theory, conglomerate discount on firm value has been explained by asymmetric information distribution, which implies that managers do not necessarily behave in the best interest of equityholders, but instead act to increase their personal wealth (see Amihud and Lev 1981; Jensen 1986; Jensen and Murphy 1990). Based on financial theory, 
Ammann and Verhofen (2006) explain and quantify the conglomerate discount using Merton's structural model and attribute the discount to the equityholders' limited liability.

\section{Corporate structures and risk and capital transfer}

Group structures differ with respect to ownership and can in principle be modeled in an integrated form, a parent-subsidiary framework, and a holding company structure. A detailed discussion covering conglomeration and regulatory issues involved in the supervision of financial conglomerates/financial groups in the European Union is given in Diereck (2004). In the following, we first present the structure of a holding company and the case of an integrated conglomerate. Based on this, we point out the special characteristics of an insurance group that is organized as a parent-subsidiary relationship.

\subsection{Holding company and integrated conglomerate}

The holding company model is a representative of the stand-alone case. As in the parent-subsidiary model, the entities fail independently and, therefore, no diversification effects occur if no transfer of assets takes place. Entities are owned by an umbrella corporation, are operationally separate and also must be separately capitalized as they have no direct access to each others' cash flows. Certain tasks, such as risk management, capital raising and allocation, or IT are typically centralized (Diereck 2004). Thus, in essence, the holding company model corresponds to the case of multiple stand-alone firms. However, due to the higher degree of centralized management, a holding company may exhibit a higher degree of correlation compared to the stand-alone situation, which can imply risk concentrations (see, e. g., Gatzert et al. 2008).

Integrated financial conglomerates have a single, consolidated balance sheet and must satisfy a single solvency capital requirement. Since capital is in principle fully fungible between the different entities, they benefit fully from diversification effects, but also face risk concentration (see Allen and Jagtiani 2000; Mälkönen 2004; Gatzert et al. 2008). In particular, losses from failing projects can be offset by returns from successful projects, which may lead to increased risk-taking behavior by the entities, i. e., moral hazard due to a "too-big-to-fail" attitude (see, e. g., Diereck 2004).

The consolidated approach is often used for the determination of diversification benefits, assuming that capital can flow freely between legal entities (Keller 2007). However, using this approach is only valid for integrated conglomerates and does not generally hold for other group structures. In particular, legal restrictions may prohibit loss compensation between different legal entities within a financial group. For instance, in the European Union, the combination of banking and insurance activities in the same legal entity is prohibited (see Article 6(1b) of the Life Insurance Directive 2002/83/EC; Article 8(1b) of the Non-Life Insurance Directive 73/239/EEC). In addition, Article 18(1) of the Life Insurance Directive prohibits combining life and non-life business in one legal entity. As these legal frameworks focus on the stabil- 
ity of an individual firm, they may contradict group interests concerning transfers of funds in case of financial distress of legal entities in the group.

\subsection{Insurance groups with risk and capital transfer instruments}

An insurance group is a collection of legal entities that are linked by ownership relation (Keller 2007). Due to legal restrictions as discussed above, an insurance group is typically organized as a parent-subsidiary structure, where entities remain legally and operationally separate. The entities are not required to cover losses of other entities in the group in the absence of legally binding capital and risk transfer instruments (CRTIs) and are separately capitalized.

In this model, two types of diversification can be distinguished. First, group diversification arises since the parent has direct access to the subsidiary's profits and thus, the market value of the subsidiary is an asset to the parent. As we assume that the subsidiary will continue in business in the case it is sold by the parent, a minimum amount of capital must remain in the firm. Hence, the subsidiary's market value cannot be fully extracted and the transferable value to the parent is restricted to certain minimum capital requirements - typically imposed by the regulator, which can be considered as regulatory costs (for the case of the Swiss Solvency Test, see, e. g., Filipovic and Kupper 2007). If assets and liabilities of parent and subsidiary are not perfectly correlated, group building is beneficial for the parent company in terms of risk reduction, while the subsidiary neither profits nor suffers disadvantages from the ownership relation.

Second, down-streaming of diversification occurs when legally binding transfer of losses contracts are signed, which are valuable for the beneficiary (parent or subsidiary). If no CRTIs are implemented, no contagion effects can occur, and only group-level diversification can arise. CRTIs are legally enforceable contractual capital and risk transfer instruments (e. g., FOPI 2006, p. 4), such as dividends, reinsurance agreements, intra-group retrocession, securitization of future cash flows, guarantees, and other contingent capital solutions. The guarantee is subject to an appropriate financial situation of the issuer to ensure the guarantee payment. These instruments serve to reduce solvency capital requirements. When the financial situation is good, capital transfers may also include transfers that are not legally binding and are conducted for, e. g., reputational reasons. In a situation of financial distress, however, only legal, contractual agreements can be enforced. If, e. g., the parent company gives the subsidiary a guarantee, CRTIs have an effect on the available economic capital of a parent company through the liabilities of the subsidiary. The guarantee leads to an increase in available economic capital for the subsidiary, and to a decrease in same for the parent. In turn, in a fair initial situation, the subsidiary's debtholders pay the parent company a fair premium for the guarantee.

However, while the available economic capital of both companies is affected by CRTIs, only the subsidiary's insolvency risk is reduced. The parent's insolvency risk is not changed as the guarantee is only paid as long as the parent remains solvent. Thus, from the perspective of policyholders, a parent-subsidiary structure with CRTIs is beneficial, for the parent's policyholders due to group level diversification 
and for the subsidiary's policyholders due to down-streaming diversification by way of CRTIs.

For group management and regulators, explicit consideration of ownership structure and the web of CRTIs are vital to assess the true extent of risk reduction through diversification and its effect on solvency capital requirements. In particular, using the consolidated approach cannot reveal actual diversification, but may be useful in detecting risk concentrations in a group (see Gatzert et al. 2008). One important point to consider is the conglomerate discount, i. e., the reduction in shareholder value through group building. This discount will dampen diversification benefits due to a decrease in equity capital.

\section{Diversification benefit and conglomerate discount}

One reason for consolidation in the first place is the realization of general diversification with respect to risk reduction (decreased capital requirements) and cost advantages. The extent of diversification effects and conglomerate discount depends on the specific organizational form and is contingent upon capital and risk transfer instruments. In the following, we first present the framework for modeling groups and individual entities and then discuss diversification measurement for financial groups in general as well as the conglomerate discount. ${ }^{2}$

\subsection{Modeling firm and group structure}

In a one period-setting, we consider a firm, where debtholders and equityholders make initial payments that are invested in the capital market. At time one, debtholders receive the value of the liabilities, and equityholders obtain the remainder of the market value of the assets. If the company is not able to cover the liabilities, the total value of the assets is distributed to the debtholders and the equityholders receive nothing. Hence, equityholders have limited liability, which can be represented in a Merton model by a call option on the firm's assets with the liabilities as the strike price. The debtholders' claims are given by the present value of the liabilities less the default put option value. The development of assets and liabilities is modeled by correlated geometric Brownian motions and valuation of the claims is conducted using risk-neutral valuation. Alternatively, jump-diffusion processes can be implemented (in this context, see, e. g., Gatzert and Schmeiser 2008b).

The capital structure in a firm is determined by the initial contributions of debtholders and equityholders. A competitive (or fair situation) requires that the initial payments of the debtholders and equityholders equal the present value of their payoff, respectively (see, e. g., Doherty and Garven 1986). Hence, the initial payment by the debtholders must equal the nominal value of liabilities less the value of the default put option at policy inception. Due to the no arbitrage condition, this described valuation implies that the payment by the equityholders equals the value of their payoff as well.

\footnotetext{
${ }^{2}$ For a detailed and formal description of the model framework, see Gatzert and Schmeiser (2008a). 
If several of these firms form a financial group, their assets and liabilities are dependent. In this respect, the modeling of the dependence structure can have a substantial influence on the diversification and shortfall risk. One way to model dependencies is using nonlinear dependencies with copulas, which allow for the inclusion of features such as fat tails and skewness for nonelliptically distributed risks (see, e. g., Gatzert et al. 2008).

\subsection{Measuring diversification}

Diversification in a financial group is typically measured based on the economic or solvency capital of a group compared to the sum of stand-alone solvency capital requirements (see, e. g., Filipovic and Kupper 2008). In this calculation, double-gearing of capital in a group should be avoided and therefore, the ownership relation must be explicitly modeled (e. g., in a parent-subsidiary setup, the market value of the subsidiary is an asset for the parent). The solvency capital is the amount of capital needed at time zero to meet future obligations over a fixed time horizon for a required confidence level $\alpha$. It can be derived based on a given capital structure of a firm or a group. Regulators expect the insurer's solvency capital not to exceed the available capital.

In the numerical analysis, we use the tail value at risk for a given confidence level to determine the necessary economic capital, as is done, e. g., in the Swiss Solvency Test (see Luder 2005; Keller 2007). The relative diversification benefit is given by the sum of solvency capital requirements $S C$ when taking into account the conglomerate structure, divided by the sum of stand-alone (solo) capital requirements:

$$
d^{\text {group }}=1-\frac{S C^{P, \text { group }}+S C^{S, \text { group }}}{S C^{P, \text { solo }}+S C^{S, \text { solo }}} .
$$

Hence, the less solvency capital the group is required to hold compared to the standalone case, the higher is the coefficient $d$, and thus the higher is the degree of diversification for the conglomerate.

We further measure risk reduction by calculating individual and joint shortfall probabilities of legal entities in a group. Shortfall is defined by the event that the available economic capital falls below zero, i. e., the insurer is insolvent if the assets are not sufficient to cover the liabilities. From the group's perspective, the joint default probabilities of exactly one $(P 1)$ or both entities $(P 2)$ are determined.

In all analysis, the ownership structure and thus the type of group are taken into account when calculating diversification benefit and shortfall risk. In the case of an insurance group, the available economic capital at time zero of parent and subsidiary remains unchanged (and hence equals the solo case), and so the solvency capital requirements remain the same. At time 1, the subsidiary's available capital is lowered by the parent's participation and increased by the CRTI from the parent to the subsidiary. The opposite effect is given for the parent, where the available capital is increased by the subsidiary's market value (limited by the minimum capital requirements to ensure that the subsidiary remains in business) and lowered by the CRTI transfer. Thus, double gearing of capital is avoided. 
In the integrated model, available capital is determined by the difference between the sum of assets and the sum of liabilities of the group's entities, since full fungibility of capital is assumed. In this case, joint shortfall is not defined in the sense described before, but coincides with the individual shortfall probabilities since both entities merge into one firm. In the case of the holding company model, diversification benefit and shortfall risk correspond to the stand-alone case of legal entities, since there are no diversification effects in our setting.

\subsection{Measuring conglomerate discount}

When comparing diversification effects and insolvency risk within different conglomerate structures, the corresponding fair capital structure differs. In particular, we expect stakeholders to adjust the capital structure in order to achieve risk-adequate returns whenever the group structure changes. When assuming that the debtholders continue to pay the same amount for their claims, the shareholder value will decrease (the conglomerate discount). Thus, the conglomerate discount refers to the observation that the total shareholder value after forming the group is lower compared to the sum of equity capital available before forming a group.

To determine the conglomerate discount, we evaluate the claims of debtholders and equityholders using risk-neutral valuation and thereby take into account the ownership relation in the group. The conglomerate discount is induced by diversification effects, which implies a risk reduction. In the Merton setting, an explanation for the conglomerate discount is given by the call option on the firm value owned by the shareholders: Lowering the volatility induces a reduction in the call option value. Diversification effects and thus risk reduction differ depending on the level of integration in the group.

To ensure comparability between the different group structures, the debtholders of the group pay the same initial amount as in the stand-alone case. In the case of the insurance group, one needs to differentiate between the situations of the parent and the subsidiary. We assume that the subsidiary separately pays a fair price for any CRTIs and thus they are not part of the fair initial equity that ensures the preset safety level without the CRTI. Furthermore, the ownership relation (the parent can sell the subsidiary for its market value) does not influence the situation for the subsidiary's debtholders. Hence, the debtholders require the same amount of equity capital in the company as would be the case without CRTI structure. Therefore, the subsidiary's initial situation in the CRTI model is identical to the stand-alone case and thus, there is no conglomerate discount.

The parent's debtholders profit from the possibility of selling the subsidiary at its market value due to the reduction in the default put option payoff. Given the same safety level in terms of the default put option value and same nominal value of liabilities (such that parent's debtholders pay the same amount with and without participation), initial equity capital can be reduced. The value of the equityholders' payoff is generally reduced through the participation due to risk reduction and hence, there is a conglomerate discount effect.

In the integrated conglomerate, a fair equity-premium combination is derived by adjusting only the equity capital of one firm, leaving everything else as in the stand- 
alone case. Since the debtholders pay the same amount and have the same claims cost distribution at time one (and the same nominal value of liabilities), to ensure a fair situation, the default put option value in the integrated conglomerate must equal the sum of stand-alone default put option values. Thus, in general, less equity capital is necessary to meet the safety level. Another explanation for the conglomerate discount in the integrated case is implied by the limited liability of the shareholders and the fact that the value of the sum of call options (before conglomeration) is higher than the value of a call option on the sum of assets less liabilities (after conglomeration) (see also Ammann and Verhofen 2006).

As the conglomerate discount implies a lower equity capital in the group, taking into account this change (fair capital structure) will lead to reduced diversification benefits with respect to solvency capital and shortfall risk compared to calculations based on a fixed capital structure.

\section{Numerical examples}

In the following examples, the main results discussed above are illustrated by comparing diversification benefits of the group for a holding company, a parent-subsidiary model, and an integrated conglomerate. This way, the effect of the level of integration on solvency capital and shortfall risk can be examined. We compare results for a fixed capital structure before and after group building and for a fair capital structure that accounts for the conglomerate discount.

In this analysis, two types of CRTIs implemented in the insurance group are considered. A guarantee from parent to subsidiary and a quota share retrocession. Under the guarantee, the parent company covers the shortfall of the subsidiary, but only to the extent that its own available capital at time 1 is at least above the minimum capital necessary for it to continue its own business. Therefore, the transfer to the subsidiary is limited. Hence, if the parent offers the subsidiary a guarantee, debt (liability) is down-streamed as equity to the subsidiary. Our other CRTI is quota share retrocession, where the parent promises to pay a share of the subsidiary's liabilities. ${ }^{3}$ In general, CRTIs can also be implemented vice versa, i. e., the subsidiary could give a guarantee to the parent.

\subsection{Input parameter}

We consider two firms - $(P)$ and $(S)$ - with the same safety level, same size, and the same payoff distribution for assets and liabilities, respectively. The safety level is measured with the default put option value, which is fixed at 0.45 for both firms and the nominal value of liabilities is given by 100, leading to a fair debtholders' contribution of 99.55. Assets and liabilities follow a geometric Brownian motion. Drift and standard deviation of the assets and liabilities of $(P)$ and $(S)$ are set to $9 \%$ and $20 \%$ (for the assets) and $1 \%$ and $17 \%$ (for the liabilities). The coefficient of correlation $\rho$

\footnotetext{
${ }^{3}$ This risk management instrument has also been considered by Filipovic and Kupper (2007) in the context of insurance groups.
} 
between assets and liabilities of each firm is given by 0.2 . The assets of one firm are not correlated with the liabilities of the second firm. The correlation between the assets of $(P)$ and $(S)$, as well as the correlation between their liabilities, are fixed at the same value, and results are derived for a coefficient of 0 and 0.7 . The riskless rate of return is $4 \%$, and the share of the subsidiary's liabilities ceded to the parent company in the case of a quota share retrocession is $5 \%$. The following study is based on Monte-Carlo simulation with 1,000,000 simulation runs using the same set of random numbers (see Glasserman 2004).

For the given initial payment of the debtholders (99.55) of firms $(P)$ and $(S)$ and with the same input parameters, the fair initial equity is 51.9 for both entities. Diversification is measured based on the tail value at risk for a confidence level of $5 \%$.

In the following, we first determine the conglomerate discount by calculating the fair equity capital for the different types of financial groups (holding, parentsubsidiary, integrated). Second, we measure diversification effects on solvency capital and shortfall risk for individual entities being part of the group. We thereby compare the case of a fixed capital structure and the case of a fair capital structure that accounts for the conglomerate discount. Third, the group's perspective is examined.

\subsection{The conglomerate discount}

Figure 1 displays the fair equity capital of legal entities $(P)$ and $(S)$ in different group structures for a coefficient of correlation $\rho$ of 0 (left hand side graph) and 0.7 (right hand side graph).

From left to right, the level of integration in the group increases, starting with the holding company, which corresponds to the stand-alone case. Since both companies are the same, the equity capital is the same as well and is given by 51.9. For the parent-subsidiary model, a decrease in the parent's shareholder value is shown due to group-level diversification since assets and liabilities of parent and subsidiary are not fully correlated. The subsidiary's fair equity capital is not affected by the ownership relation, as there are no risk reduction effects.

When introducing capital and risk transfer in the form of a guarantee or retrocession (third and fourth case in Fig. 1), the fair equity capital is not affected either.
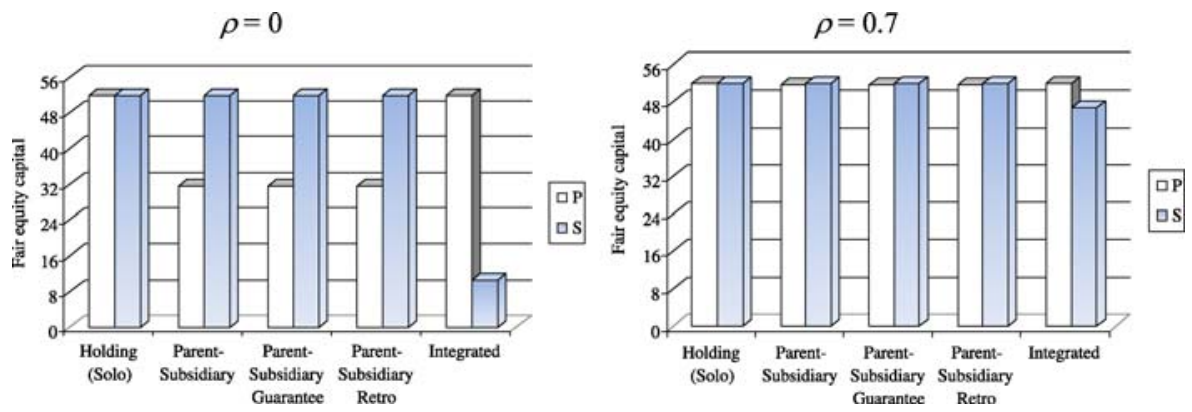

Fig. 1 Measuring the conglomerate discount: Fair capital structure for different group structures for two firms $((P)$ and $(S))$ 
This is due to the fact that CRTIs are paid separately for by the subsidiary and serve to further increase the safety level above the level granted by the available equity capital. The highest conglomerate discount is observed for an integrated financial group, i. e., the consolidated approach. This result points out the importance of distinguishing between types of group when calculating diversification effects and illustrates that the consolidated approach would overestimate the impact of diversification when a group is in fact organized as a parent-subsidiary structure.

We further observe that a high correlation coefficient $\rho$ of 0.7 between the two firms constituting the group implies a strong reduction in diversification effects and thus a much less distinct reduction of equity capital. In the following, the fair equity capital in Fig. 1 and the debtholders" initial payment are referred to as "fair capital structure".

\subsection{Diversification effects for individual entities in the group}

We next study the effect of the group structure and CRTIs on the diversification benefits of individual firms by calculating solvency capital and shortfall risk (Figs. 2 and 3). Figure 2 contains results for a zero correlation $\rho=0$ between the entities, and Fig. 3 contains the same analysis for positive correlation of $\rho=0.7$. The left column shows diversification effects for the fixed capital structure, where equity capital is assumed to be the same before and after group building ("Fixed capital structure"). The right column display results when accounting for the conglomerate discount, i. e.,

Fixed capital structure Solvency capital

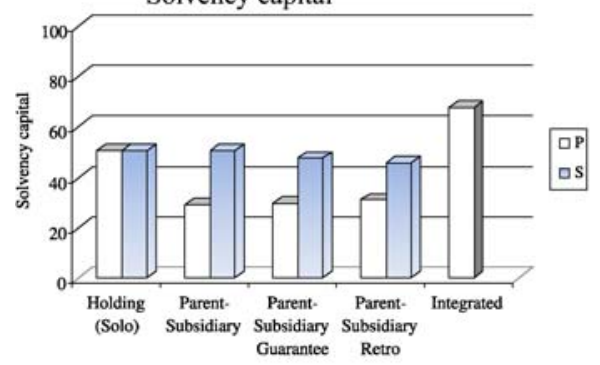

Shortfall probability $S P$

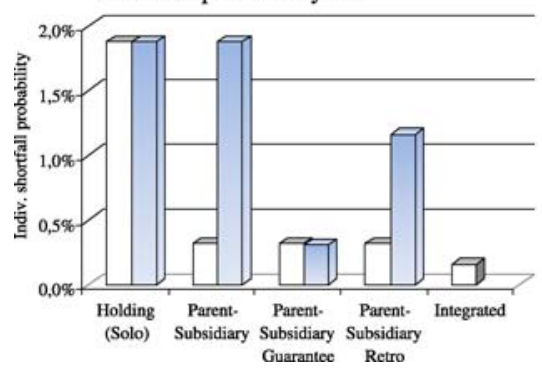

Fair capital structure

Solvency capital

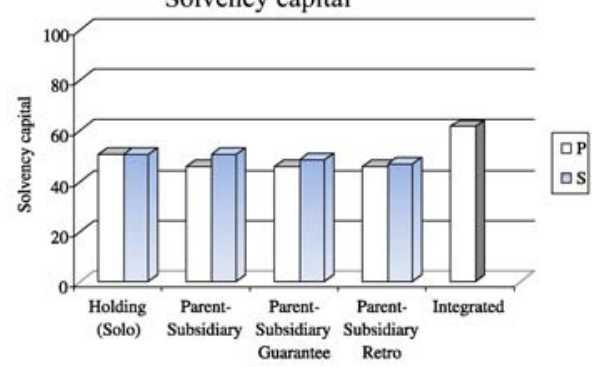

Shortfall probability $S P$

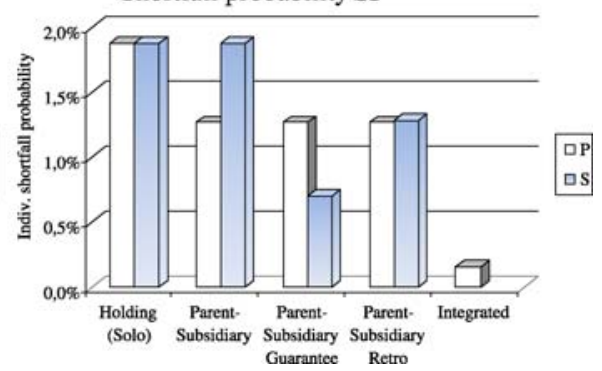

Fig. 2 Individual firm perspective for two firms $(P)$ and $(S)$ with $\rho=0$ 
Fixed capital structure

Solvency capital

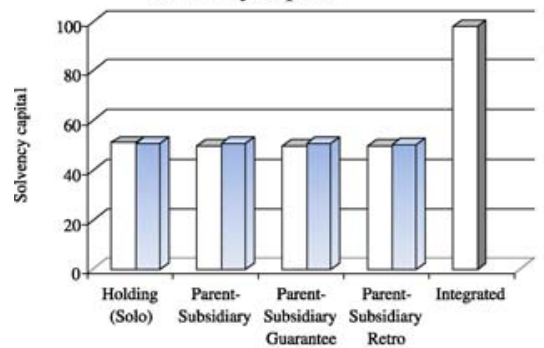

Shortfall probability $S P$

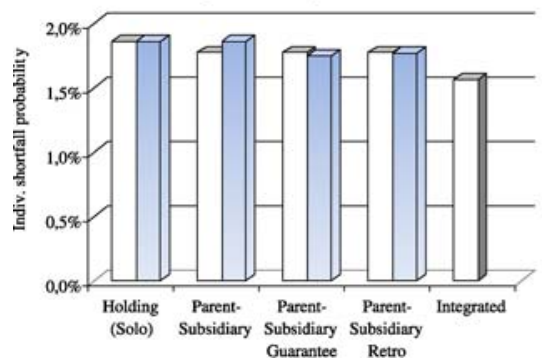

Fair capital structure

Solvency capital

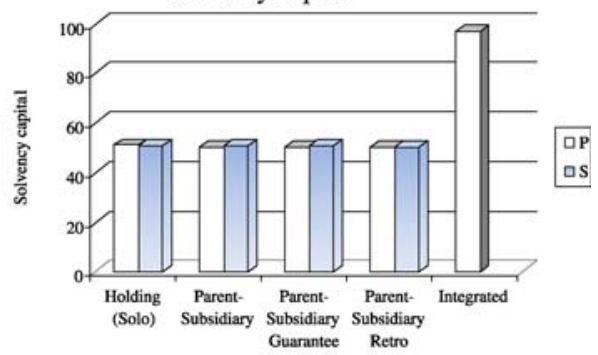

Shortfall probability $S P$

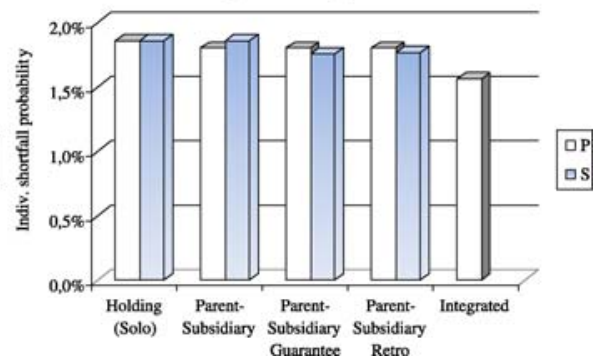

Fig. 3 Individual firm perspective for two firms $(P)$ and $(S)$ with $\rho=0.7$

when measuring diversification based on the fair capital structure in Fig. 1 where equity capital is reduced.

The first row in Fig. 2 shows the solvency capital requirements, and the second row contains individual shortfall probabilities. Compared to the holding company, the parent-subsidiary model allows a reduction in solvency capital for the parent due to group-level diversification effects, while the subsidiary's requirement remains unchanged. The introduction of a guarantee and a retrocession implies a slightly lower solvency capital for the subsidiary due to down-streaming diversification and increases the parent's solvency capital. For the same reasons, diversification leads to much lower shortfall probabilities for the parent as well as the subsidiary. In particular, we observe the previously discussed effect that the parent's shortfall risk is substantially reduced through the ownership relation, but not affected by offering CRTIs since guarantee payments are only made if the parent's financial situation allows for it. For the subsidiary, in contrast, CRTIs imply a lower shortfall risk.

However, diversification benefits are substantially dampened when accounting for the conglomerate discount effect. Solvency capital and shortfall probability in the right column "Fair capital structure" in Fig. 2 are much less pronounced than if assuming a fixed capital structure (see left column in Fig. 2). Furthermore, when conducting the same analysis for highly positively correlated assets and liabilities of entities within the group (Fig. 3), we find that diversification effects are low and, hence, that the results for the fair capital structure do not differ much from the fixed capital structure (see also Fig. 1). 
Fixed capital structure

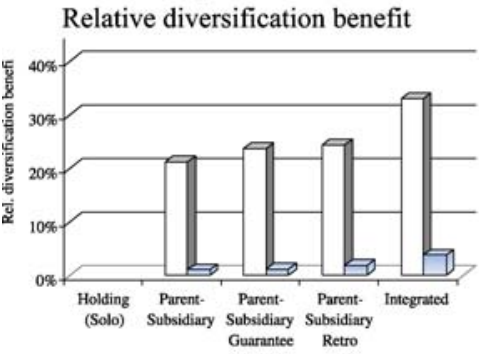

Joint shortfall probability $\rho=0$

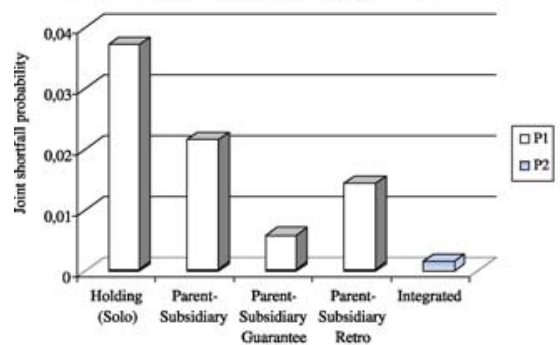

Joint shortfall probability $\rho=0.7$

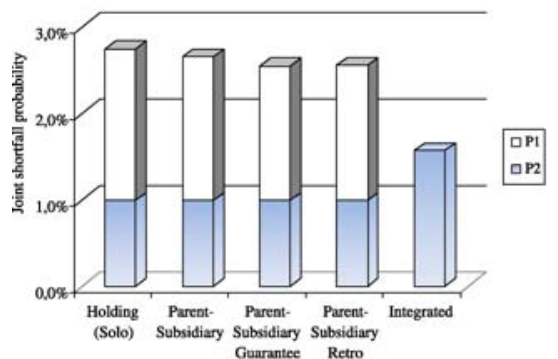

Fair capital structure

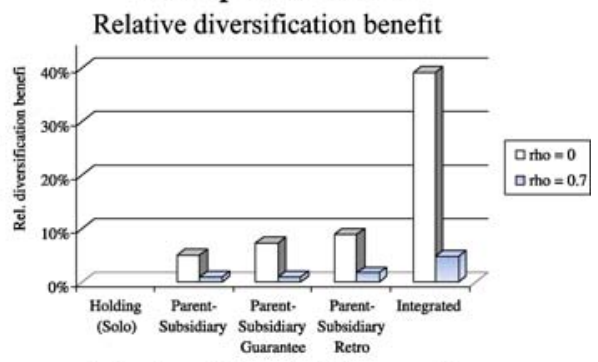

Joint shortfall probability $\rho=0$

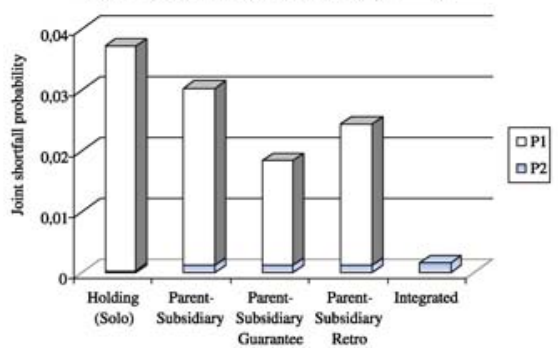

Joint shortfall probability $\rho=0.7$

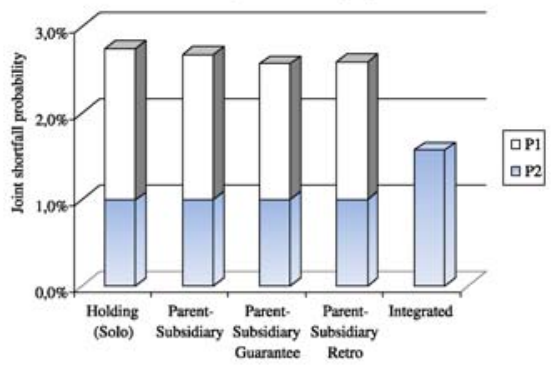

Notes: $P 1=$ probability that exactly one entity defaults; $P 2=$ probability that both entities default at the same time.

Fig. 4 Diversification effects from the group perspective

5.4 Diversification effects from the group perspective

Diversification effects from the viewpoint of the group are laid out in Fig. 4. The relative diversification benefit is determined as the sum of solvency capital for entities being part of the group structure divided by the sum of solvency capital on a standalone basis. In addition, we compute joint shortfall probabilities, including the probability that exactly one of the two companies defaults $(P I)$ and the probability that both companies default at the same time $(P 2)$. Shortfall risk is provided for $\rho=0$ and for $\rho=0.7$. Again, we compare the cases of a fixed capital structure and a fair capital structure.

First, the diversification benefit increases with increasing level of integration in the group. The highest diversification benefit is obtained for the integrated conglomerate. 
In addition, CRTIs serve to increase the diversification benefit for the whole group compared to the parent-subsidiary model without CRTIs. For a high correlation coefficient $\rho$ of 0.7 , diversification effects with respect to relative diversification benefit and shortfall risk are low. At the same time, the probability that both entities default simultaneously is much higher. As observed previously, we find that diversification effects from the group's perspective are substantially reduced when considering the conglomerate discount, i. e., the fair capital structure. This also includes the effect that joint shortfall risk is not as much reduced as one may expect when basing the analysis on a fixed capital structure.

\section{Summary}

This article studies diversification and shortfall risk for different financial groups. We particularly focus on insurance groups modeled as parent-subsidiary structures and examine the benefits of capital and risk transfer instruments. In the analysis, we explicitly account for the conglomerate discount, which is the reduction of shareholder value due to diversification. This effect is typically ignored in the literature when determining diversification benefits. Our results illustrate that in general, group solvency requirements decrease with increasing level of integration and that diversification effects and conglomerate discount are alleviated when cash flows between legal entities in a financial group are highly correlated.

For an insurance group in a parent-subsidiary structure, we show that the ownership relation reduces the parent's shortfall risk compared to solo case, since the value of the subsidiary is an asset for the parent. In contrast, the subsidiary's shortfall probability remains unaffected by ownership relation. However, capital and risk transfer instruments from parent to subsidiary can reduce the subsidiary's shortfall risk and solvency capital requirements but do not affect the parent's solvency situation. Thus, risk and capital transfer instruments increase the diversification benefit of the whole group and serve to reduce solvency capital requirements.

A main finding is that diversification effects are much lower when taking into account the conglomerate discount effect. This is caused by the reduction in equity capital after forming a group compared to the case of a fixed capital structure before and after group building. Hence, diversification of risks does not matter to the extent emphasized in the literature so far. Overall, we conclude that for decisions regarding group capital regulation and group enterprise risk management, it is important to consider conglomerate discount effects when measuring diversification effects and to properly model group structures and ownership relation along with CRTIs in order to receive firm conclusions.

\section{References}

Allen, L., Jagtiani, J.: The risk effects of combining banking, securities, and insurance activities. J. Econ. Bus. 52(6), 485-497 (2000)

Amihud, Y., Lev, B.: Risk reduction as a managerial motive for conglomerate mergers. Bell J. Econ. 12(2), 605-618 (1981) 
Ammann, M., Verhofen, M.: The conglomerate discount: A new explanation based on credit risk. Int. J. Theor. Appl. Finance 9(8), 1201-1214 (2006)

Berger, P., Ofek, E.: Diversification's effect on firm value. J. Financial Econ. 37(1), 39-65 (1995)

Diereck, F.: The supervision of mixed financial services groups in europe. European Central Bank Occasional Paper Series No. 20 (August 2004) (2004)

Doherty, N.A., Garven, J.R.: Price regulation in property-liability insurance: A contingent-claims approach. J. Finance 41(5), 1031-1050 (1986)

Federal Office of Private Insurance (FOPI): Draft modeling of groups and group effects. Available at: www.bpv.admin.ch (2006) Accessed 10.02.2008.

Filipovic, D., Kupper, M.: On the group level swiss solvency test. Bull. Swiss Assoc. Actuar. 1, 97-115 (2007)

Filipovic, D., Kupper, M.: Optimal capital and risk transfers for group diversification. Math. Finance 18(1), $55-76(2008)$

Freixas, X., Loranth, G., Morrison, A.D.: Regulating financial conglomerates. J. Financial Intermed. 16(4), 479-514 (2007)

Gatzert, N., Schmeiser, H.: On the risk situation of financial conglomerates: Does diversification matter? Working Paper on Risk Management and Insurance, University of St. Gallen (2008a)

Gatzert, N., Schmeiser, H.: The influence of corporate taxes on pricing and capital structure in propertyliability insurance. Insur.: Math. Econ. 42(1), 50-58 (2008b)

Gatzert, N., Schmeiser, H., Schuckmann, S.: Enterprise risk management in financial groups: Analysis of risk concentration and default risk. Working Paper on Risk Management and Insurance, University of St. Gallen. Financial Mark. Portf. Manag. 22(3), 241-258 (2008)

Glasserman, P.: Monte Carlo Methods in Financial Engineering. Springer, New York (2004)

Jensen, M.: Agency costs of free cash flow. Am. Econ. Rev. 76(2), 323-329 (1986)

Jensen, M., Murphy, K.J.: Performance pay and top-management incentives. J. Political Econ. 98(2), 225-264 (1990)

Keller, P.: Group diversification. Geneva Pap. Risk Insur. - Issues Pract. 32(3), 382-392 (2007)

Laeven, L., Levine, R.: Is there a diversification discount in financial conglomerates? J. Financial Econ. 85(2), 331-367 (2005)

Luder, T.: Swiss solvency test in non-life insurance. Working Paper, presented at the ASTIN Colloquium 2005 (2005)

Luder, T.: Modelling of risks in insurance groups for the Swiss solvency test. Bull. Swiss Assoc. Actuar. 1, 85-97 (2007)

Mälkönen, V.: Capital adequacy regulations and financial conglomerates. Bank of Finland Research Discussion Paper No. 10/2004 (2004) 